\title{
Identifying Factors Preventing Sustainable Brand Loyalty among Consumers: A Mixed Methods Approach
}

\author{
Xin Zhang, Xiaoyan Ding * (D), Liang Ma and Gaoshan Wang \\ School of Management Science and Engineering, Shandong University of Finance and Economics, Jinan 250014, \\ China; zhangxin@sdufe.edu.cn (X.Z.); maliang@mail.sdufe.edu.cn (L.M.); wgs6107@126.com (G.W.) \\ * Correspondence: dingxiaoyan92@163.com; Tel.: +86-183-6617-8337
}

Received: 13 November 2018; Accepted: 5 December 2018; Published: 10 December 2018

\begin{abstract}
Consumers' brand-switching behavior, or the non-sustainability of consumer loyalty to a brand, brings huge losses to affected companies. Thus, the investigation of factors behind consumers' brand-switching is very important. The study analyzes the mechanism and configuration of brand-switching intention in order to provide guidelines for increasing brand competitiveness. Using empirical analysis (SEM) and qualitative comparative analysis (fsQCA), this study elucidates the motives and mechanisms in operation when customers decide whether to stay with a particular brand or switch to an alternative. The data was collected in August 2017. The results of SEM showed that the attractiveness of an alternate brand had a negative influence on current brand image recognition and brand value recognition, which could produce negative emotions that then lead to a brand-switching intention. The fsQCA uncovered six combinations or configurations of variables that could lead to brand-switching. This study has both theoretical and practical outcomes for competitive branding.
\end{abstract}

Keywords: brand-switching intention; alternative attractiveness; brand recognition; brand emotion; website anxiety

\section{Introduction}

An increasing number of consumers switch from one brand to another, and a loss of customer base can damage the long-term development of a new company as well as decrease its profits. According to statistics, the cost of acquiring a new customer is far greater than that of maintaining an existing customer [1]. The aim of brand management is to build a healthy relationship with customers and thus enhance brand loyalty [2]. However, rapid development of product homogeneity is exacerbating the potential for consumers to switch brands. Determining which factors influence brand-switching and how to exploit them is of vital importance for companies trying to hold on to their clientele.

According to marketing strategists, loyalty among customers is influenced by both 'push' (display advertising, promotions, mailings) and 'pull' (customer relations, word-of-mouth, advertising campaigns) factors [3]. From the push perspective, research affirms that brand recognition influences brand selection and switching intentions [4]. Word-of-mouth criticisms of a brand can also lead to brand-switching [5]. The perceived attractiveness of alternative products plays a significant role in customer choice and influences the desire of customers to try a different brand [6]. While there have been few studies of external pull factors such as alternative product attractiveness [7], the rapid development of product homogeneity exacerbates the potential for consumers to switch brands, which means that the role of external substitute attraction cannot be ignored. In addition, the complexity of consumer brand-switch intentions equates to a relatively complicated formation path 
for brand conversion intentions; however, most research has directly addressed the factors influencing brand-switching [4-6] rather than systematically analyzing the internal influencing mechanism and effective formation path of brand conversion intentions. To fill these gaps, our study utilized cognition theory in order to explore the mechanisms and configurations of brand-switching intention. Alternative attractiveness, negative brand image recognition, negative brand value recognition, negative brand emotion and website anxiety were included in this study in order to determine their mutual effects on the decision to stay with a particular brand or to switch to a new one.

This paper is organized into specific sections. Following the introduction in Section 1, the theoretical background is discussed and a literature review is presented in Section 2; the research model and hypotheses are also considered. In Section 3, the research methodology, including measurement and data collection, is described, and in Section 4 the data is analyzed. Section 5 includes discussion and interpretation of the results, and the conclusions are summarized, offering some theoretical and practical implications. Lastly, this study considers the limitations and raises the prospect of future studies in Section 6.

\section{Theoretical Background and Hypotheses}

\subsection{Cognition Theory and the Framework of Brand Intention}

Cognition theory explains the mechanism of how people's cognitive abilities influence information processing and subsequent behavior. According to cognition theory, there exist mutual and dynamic effects between an individual's environment and their perception of that environment, resulting in deterministic behavior. On this basis, it is assumed that the major determinant of people's behavior is their subjective cognition [8]. These ideas can be applied to understand and predict individual behavior, which from a marketing standpoint could also help to discern the key factors influencing an individual's behavior towards a particular brand of product. In the context of e-commerce, customers are confronted with myriad brands, which can result in confusion and frustration for the customer [9]. Perceptions of brand superiority or inferiority are the major drivers of product loyalty, and any change in marketing can prompt brand-switching. This process of selecting a brand involves information processing and cognition, which could play a vital role in user behavior. Therefore, cognition theory is well suited in the e-commerce context to exploring the mechanism and configuration of brand-switching intention.

Some scholars have applied the stereotype content model in the context of brand recognition to determine how the framework of brand intention influences brand loyalty [10]. Within a framework of brand intention, the brand image is not considered to be a passive receiver of customers' behavior, but rather an active entity that can send valuable information to customers. The relationship between customer and brand is influenced by both inside and outside factors, just as between two people [11]. From a perspective inside the brand, customers would develop certain forms of recognition in the process of relating to the brand. They would judge the brand according to their intentions and abilities, including their recognition and personal evaluation, as well as how the product is viewed by their friends. From a perspective outside the brand, comparison with alternative products, each with their own persuasive intentions, also has a strong effect on which brand a customer will decide to go with. Thus, the brand acts as an intentional body, and it is perceived that the establishment of brand recognition is similar to the building of an interpersonal relationship. In the context of e-commerce, a brand-switching intention demonstrates a customer's intention to discard the current brand and switch to a new one, thus reflecting an intention towards a certain alternative brand. Thus, this study also applied the framework of brand intention to the investigation of brand-switching intention.

People sometimes endow brands with personal characteristics, generating a strong attachment to a particular brand [12]. Research indicates that emotion is a powerful motivator of behavior and could mediate the relationship between recognition and behavior [13]. The framework of brand intention shows that viewing a brand as an intentional body fits the same basic form of "recognition-emotion-behavior", so the role of brand emotion should also be considered in studying 
the mechanism of brand-switching. Therefore, based on both the cognition theory and the framework of brand intention, this study investigated the mechanism and configuration of brand-switching intention.

\subsection{Research Hypotheses}

Research has shown that brand recognition and brand value are core elements in the purchasing process [14]. If the product does not satisfy the customer's needs, they will think that the brand is inferior in performance, and this could lead to decreased brand recognition. From a perspective inside the brand, research shows that brand congruity significantly influences brand recognition [15]. From a perspective outside the brand, the attractiveness of competing products also plays an important role in pulling a customer's behavior, competing with push factors [16]. Confronted with powerful attractions, some customers will decide to compare the current brand with its alternatives and judge which one they think is better. If an alternative product appears superior to their current one, the customer's attachment to the product may decrease, leading to a passive attitude in which they think less of its brand image and value. This study follows Aaker [17] in dividing negative brand recognition into two dimensions of negative brand image recognition and negative brand value recognition. According to the above discussion, it is assumed that alternative attractiveness could have a significant influence on how customers cognize the brand image and brand value. Therefore, this study poses the following hypotheses:

H1: Alternative attractiveness positively influences negative brand image recognition.

H2: Alternative attractiveness positively influences negative brand value recognition.

Cognition, emotion and behavior are the fundamental elements in motivating a customer to take action. Research confirms that the effects of emotions in determining behavior are stronger than the effects of cognition. In the context of e-commerce, cognition refers to the intellectual bias towards a product or brand, the emotional aspect includes the feelings and psychological attachment towards the product, and behavior is related to customer's intention to take action. Brand recognition shows how customers perceive the brand's characteristics, performance, etc. Cognition creates a channel for the consumer to receive information about the product and to establish connections with the brand, which could help to generate emotions towards the brand. It has been shown that brand recognition has a significant role in customers' feelings [18]. The effect of brand recognition on customer preference is also significant [19]. It could be inferred that brand emotion could be influenced by brand recognition. Once customers cognize less towards the brand, they have a tendency to pour less emotion towards it. According to the framework of brand intention, brand emotion is a psychological effect compared to cognitive and behavioral intention. The effects of brand emotion have received a lot of attention in e-commerce. Concerning the outcomes of brand emotions, some scholars have demonstrated that brand emotion could significantly influence a customer's behavior towards a product. For example, brand emotion influences purchase intention [20], brand equity [21], and brand loyalty [22,23]. Brand emotion also strongly influences brand extension [24]. In this study, it is assumed that brand recognition could have an effect on brand emotion, which could further lead to intention. Therefore, this study proposes the following hypotheses:

H3: Negative brand image recognition positively influences negative brand emotion.

H4: Negative brand value recognition positively influences negative brand emotion.

H5: Negative brand emotion positively influences brand-switching intention.

Website anxiety is defined as the apprehension that individuals experience when using a website [25]. It is shown that website anxiety has a negative effect on a user's intentions to continue using the product or service promoted by the site. For example, online shoppers who begin to feel too anxious do not buy as much [26]. Likewise, those who worry about smartphone use are less likely to continue the service [27]. Anxiety could also lead to problematic use [28] and protective behavior [29]. 
However, a study by $\mathrm{Xu}$ [25] showed that website anxiety had no influence on an individual's intention to return to a website. In this study, it is assumed that if consumers feel anxiety while engaging in e-commerce, they have less energy and this could decrease behavioral intentions. That is to say, website anxiety is a significant factor in a customer's intention to switch; thus, the role of website anxiety is taken into consideration when investigating the mechanism and configuration of brand-switching intention. Therefore, this study raises the following hypothesis:

H6: Website anxiety positively influences brand-switching intention.

The research model is shown in Figure 1.

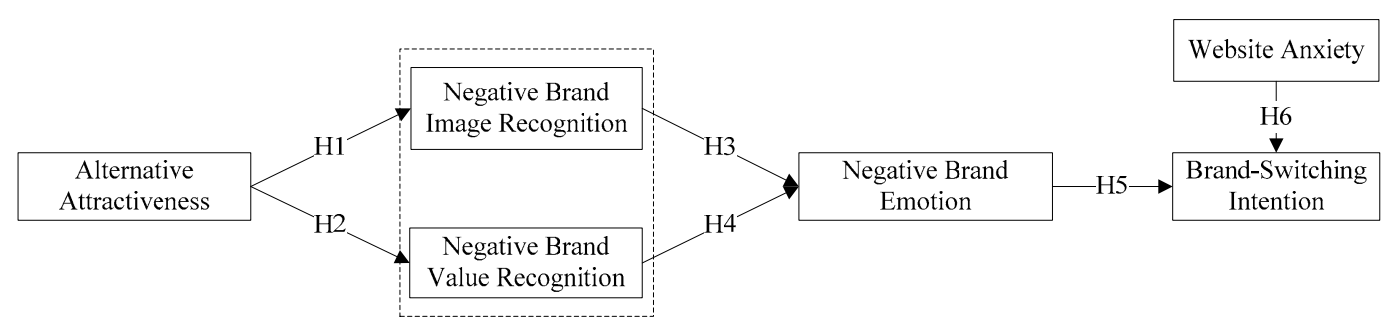

Figure 1. Research model.

\section{Research Methodology}

\subsection{Measurements}

In the empirical study, an online survey was conducted using a battery of questions designed to collect participants' data about the relative influence of brand attractiveness, recognition, value, associated emotions, and website anxiety on shoppers' intentions to purchase a different brand of product. The measurements of negative image recognition and negative brand value recognition were based on previous studies [30,31]. The measurement of alternative attractiveness was based on the study of Ping Jr [32], negative brand emotion on Thomson, et al. [33], website anxiety on Xu [25] and brand-switching intention on the study of Han, et al. [34]. All responses were based on a 7-point Likert scale ranging from 1 (strongly disagree/unlikely) to 7 (strongly agree/likely).

\subsection{Data Collection}

An online survey was used to determine how a specific set of cognitive and emotional factors affected a person's decision to switch to a different product brand. For credibility and diversity, this study collected the questionnaire with the assistance of a leading Chinese internet research firm, Sojump.com, a platform that has been used in numerous previous studies [35,36]. The data was collected in August 2017, and all of the participants were required to have had an online shopping experience. In total, 227 questionnaires were collected and, after deleting 26 invalid responses, 201 valid questionnaires were kept for data analysis. Among the valid questionnaires, 97 were from males (48.3\%) and 104 from females (51.7\%). 108 respondents were over forty years old. There were 189 with a bachelor's degree or higher. 170 respondents had an income of more than 3000 yuan, and 171 had online shopping experience of more than three years. These demographic characteristics are representative of the current population structure in China and thus were suitable for our research context. The demographic characteristics are shown in Table 1. 
Table 1. Descriptive statistics of the respondents.

\begin{tabular}{|c|c|c|c|}
\hline Demographic Variables & Characteristics & Frequency & $\%$ \\
\hline \multirow{2}{*}{ Gender } & Male & 97 & 48.3 \\
\hline & Female & 104 & 51.7 \\
\hline \multirow{6}{*}{ Age } & $<20$ & 1 & 0.5 \\
\hline & $20-25$ & 37 & 18.4 \\
\hline & $26-30$ & 70 & 34.8 \\
\hline & $31-40$ & 62 & 30.8 \\
\hline & $41-50$ & 23 & 11.4 \\
\hline & $>50$ & 8 & 4.0 \\
\hline \multirow{3}{*}{ Occupation } & Student & 16 & 8.0 \\
\hline & Office worker & 158 & 78.6 \\
\hline & Other & 27 & 13.4 \\
\hline \multirow{4}{*}{ Education level } & College less & 41 & 20.4 \\
\hline & College & 138 & 68.7 \\
\hline & Graduate & 19 & 9.5 \\
\hline & Doctor & 3 & 1.5 \\
\hline \multirow{5}{*}{ Income } & $<3000$ & 31 & 15.4 \\
\hline & $3000-5000$ & 61 & 30.3 \\
\hline & $5000-8000$ & 72 & 35.8 \\
\hline & $>8000$ & 37 & 18.4 \\
\hline & $>15,000$ & 17 & 8.5 \\
\hline \multirow{4}{*}{ Years of using SNS } & $<1$ & 9 & 4.5 \\
\hline & $1-3$ & 37 & 18.4 \\
\hline & $3-5$ & 91 & 45.3 \\
\hline & $>5$ & 85 & 42.3 \\
\hline
\end{tabular}

\section{Data Analysis}

\subsection{Measurement Validation}

Smart PLS 2.0 software was used for the empirical study to check for reliability and validity. Data was first checked for reliability using Cronbach's $\alpha$, composite reliability (CR) and average variance extraction (AVE). The validity was verified through factor loadings, composite reliability (CR) and average variance extraction (AVE). For validity acceptance, Cronbach's $\alpha$, factor loading, and CR should be more than 0.7 and AVE should be more than 0.5 [37]. This study also checked discriminant validity which is correct if the square of the construct's AVE is larger than the correlation with other constructs. The results show that our structural model has good reliability and validity (Tables 2 and 3 ).

Table 2 . The reliability and validity.

\begin{tabular}{cccccccccc}
\hline Iems & Cronbach's Alpha & CR & AVE & AA & BE & BI & BS & BV & WA \\
\hline AA & 0.868 & 0.919 & 0.791 & 0.890 & & & & & \\
BE & 0.897 & 0.936 & 0.829 & 0.681 & 0.911 & & & & \\
BI & 0.746 & 0.856 & 0.665 & 0.588 & 0.728 & 0.815 & & & \\
BS & 0.887 & 0.922 & 0.747 & 0.698 & 0.846 & 0.773 & 0.864 & & \\
BV & 0.789 & 0.876 & 0.703 & 0.597 & 0.787 & 0.768 & 0.824 & 0.838 & \\
WA & 0.862 & 0.906 & 0.707 & 0.651 & 0.502 & 0.581 & 0.563 & 0.514 & 0.841 \\
\hline
\end{tabular}


Table 3. The factor loading of the constructs.

\begin{tabular}{ccccccc}
\hline Iems & AA & NBE & NBI & BS & NBV & WA \\
\hline AA1 & 0.897 & & & & & \\
AA2 & 0.852 & & & & & \\
AA3 & 0.918 & & & & & \\
NBE1 & & 0.902 & & & & \\
NBE 2 & & 0.908 & & & & \\
NBE3 & & 0.921 & & & & \\
NBI1 & & & 0.868 & & & \\
NBI2 & & & 0.796 & & & \\
NBI3 & & & 0.779 & & & \\
BS1 & & & & 0.843 & & \\
BS2 & & & & 0.888 & & \\
BS3 & & & & 0.877 & & \\
BS4 & & & & 0.848 & & 0.795 \\
NBV1 & & & & & 0.845 & \\
NBV2 & & & & & 0.873 & \\
NBV3 & & & & & & 0.849 \\
WA1 & & & & & 0.798 \\
WA2 & & & & & 0.845 \\
WA3 & & & & &
\end{tabular}

\subsection{Structural Results and Hypotheses Testing}

Smart PLS 2.0 software was used to verify the hypotheses. The structural equation model (SEM) results show that alternative attractiveness positively influences negative brand image recognition ( $\beta=0.588, t=9.405)$ and negative brand value recognition $(\beta=0.597, t=10.347)$. Thus, hypotheses $\mathrm{H} 1$ and $\mathrm{H} 2$ are supported. In addition, negative brand image recognition $(\beta=0.301, \mathrm{t}=3.009)$ and negative brand value recognition $(\beta=0.556, t=5.984)$ positively influence negative brand emotion. Therefore, the hypotheses $\mathrm{H} 3$ and $\mathrm{H} 4$ are supported. Finally, negative brand emotion $(\beta=0.753$, $\mathrm{t}=17.462)$ and website anxiety $(\beta=0.185, \mathrm{t}=3.660)$ positively influence brand-switching intention. Therefore, the hypotheses $\mathrm{H} 5$ and $\mathrm{H} 6$ are supported. The results are shown in Figure 2.

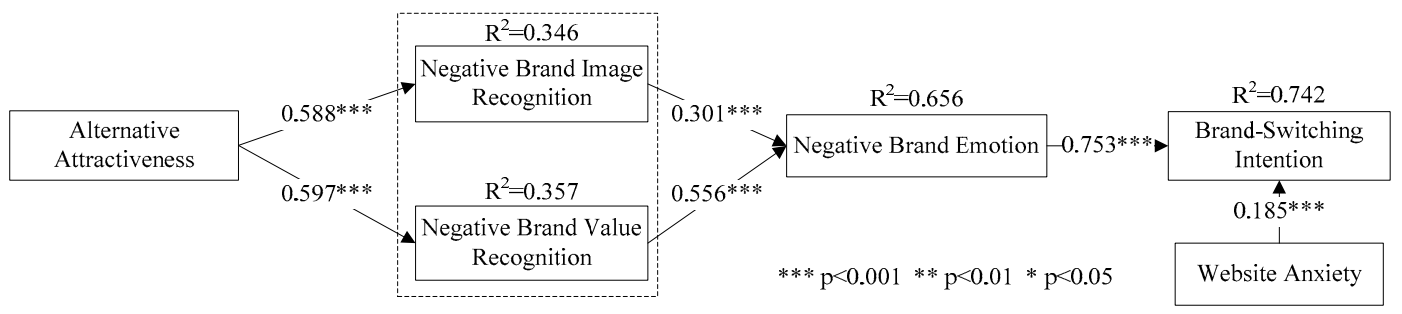

Figure 2. Results of the research model.

Next, this study analyzed the mediating role of negative brand emotion in the relationships between negative brand image recognition and brand-switching intention, and between negative brand value recognition and brand-switching intention. The results show that negative brand emotion partially mediated the relationships between negative brand image recognition and brand-switching intention, and between negative brand value recognition and brand-switching intention (Table 4). 
Table 4. The mediating role of negative brand emotion in the relationships between negative brand image recognition, negative brand value recognition and brand-switching intention.

\begin{tabular}{ccccccccc}
\hline \multirow{2}{*}{ Path } & \multirow{2}{*}{ Effect } & \multicolumn{2}{c}{ Coefficient } & \multicolumn{2}{c}{ Bias-Corrected } & \multicolumn{2}{c}{ Percentile } \\
\cline { 5 - 9 } & & & SE & $\mathbf{t}$ & \multicolumn{2}{c}{$\mathbf{9 5 \% C I}$} & & \multicolumn{2}{c}{$\mathbf{9 5} \% \mathbf{C I}$} \\
\hline Negative brand image & Direct & 0.336 & 0.050 & 6.748 & 0.238 & 0.434 & 0.238 & 0.434 \\
recognition->brand-switching intention & Indirect & 0.437 & 0.064 & 6.828 & 0.326 & 0.581 & 0.326 & 0.581 \\
\hline Negative brand value & Direct & 0.413 & 0.053 & 7.777 & 0.308 & 0.518 & 0.308 & 0.518 \\
recognition->brand-switching intention & Indirect & 0.408 & 0.063 & 6.476 & 0.298 & 0.541 & 0.295 & 0.538 \\
\hline
\end{tabular}

\subsection{Re-Analysis of the Data Using $f_{s} Q C A$}

This study used the fuzzy-set qualitative comparative analysis (fsQCA) method to study the configuration of brand-switching intention. The fsQCA draws on the concepts of necessary and sufficient conditions, analyzing which conditions are necessary or sufficient for a certain result to arise within complex causal structures. This method tries to identify patterns of elements leading to an outcome, and goes to a step further from the mere identification of correlations among independent and dependent variables. That is to say, the fsQCA offers an innovative approach and allows a detailed analysis of how causal conditions contribute to a particular result, and draws on a configurational understanding of how a combination of causes leads to the same series of results.

The fsQCA software was used to extracted the constructs of alternative attractiveness, negative brand image recognition, negative brand value recognition, negative brand emotion and website anxiety to explore their mutual effects on brand-switching intention. For the present study, the outcome is 'brand-switching intention' (BS), and the antecedents examined, following the calibration procedure, are 'alternative attractiveness' (AA), 'negative brand image recognition' (NBI), 'negative brand value recognition' (NBV), 'negative brand emotion' (NBE) and 'website anxiety' (WA). The questions relating to these measures also correspond to values on a seven-point Likert scale.

In the first step of the qualitative analysis process, the study converted the raw data into fuzzy-set responses. Firstly, the condition and outcome variables' values were transformed from interval-scale values to fuzzy-membership scores in the range 0 (full exclusion "non-membership" from a set) to 1 (full inclusion "membership" in a set) [38] to construct a "continuous" fuzzy set for each variable. Secondly, the value of each construct was calibrated according to the three thresholds of $25 \%, 50 \%$, and $75 \%$. The calibration involved the use of "the direct method" outlined by L. Morgan [39], which implies transforming the interval, using a crossover point as an anchor to calculate the deviation scores, and taking the values of pertinence as the upper or lower boundaries. To calibrate these observations, the interval was divided into two different measures, whose values are between 0 and 1. These values do not represent probabilities but rather transformations of the quantitative scales in degrees of integration within the category [40]. Finally, necessary and sufficient condition tests evaluated the effect of the different variables on brand-switching intention. The fsQCA generates three possible solutions: complex, parsimonious and intermediate. This study presents the latter. The results are shown in Table 5.

Considering the necessary conditions test in Table 5, negative brand image recognition (NBI), negative value recognition (NBV), negative brand emotion (NBE) and website anxiety (WA) were necessary conditions for brand-switching intention because their consistency values were above 0.9 [41]. Alternative attractiveness (AA) was the only exception.

Regarding sufficient conditions, all variables were present for the occurrence of brand-switching intention. The results of intermediate solutions indicated that there were six combinations of causal conditions that could form brand-switching intention (Table 6). A model is considered informative when consistency is above 0.74 in fsQCA [42]. 
Table 5. Analysis of necessary condition (the value of outcome variable is 1).

\begin{tabular}{cc}
\hline Construct & Consistency \\
\hline aa & 0.885 \\
$\sim$ aa & 0.416 \\
nbi & 0.947 \\
$\sim$ nbi & 0.366 \\
nbv & 0.951 \\
$\sim$ nbv & 0.374 \\
nbe & 0.921 \\
$\sim$ nbe & 0.394 \\
wa & 0.872 \\
$\sim$ wa & 0.442
\end{tabular}

Note: $\sim$ demonstrate null. The same in the following.

Table 6. The intermediate solution.

\begin{tabular}{|c|c|c|c|}
\hline \multicolumn{4}{|c|}{ frequency cutoff: 1.000} \\
\hline \multicolumn{4}{|c|}{ consistency cutoff: 0.864} \\
\hline \multicolumn{4}{|c|}{ Assumptions: aa; nbi; nbv; nbe; wa (present) } \\
\hline & Raw coverage & Unique coverage & Consistency \\
\hline nbvnbi & 0.916 & 0.063 & 0.949 \\
\hline$\sim \mathrm{aa}^{*} \sim \mathrm{wa}^{*} \sim$ nbe & 0.305 & 0.001 & 0.840 \\
\hline $\mathrm{wa}^{*} \sim \mathrm{nbe}^{*} \sim \mathrm{nbv}$ & 0.315 & 0.001 & 0.925 \\
\hline$\sim \mathrm{wa}^{*} \sim \mathrm{nbe}^{*} \mathrm{nbv}$ & 0.323 & 0.001 & 0.934 \\
\hline aa*nbe*nbv & 0.823 & 0.014 & 0.981 \\
\hline aa*wa*nbi & 0.792 & 0.015 & 0.968 \\
\hline \multicolumn{4}{|c|}{ solution coverage: 0.954} \\
\hline \multicolumn{4}{|c|}{ solution consistency: 0.894} \\
\hline
\end{tabular}

Therefore, the coverage (0.954) and consistency (0.894) of the six conditions were adequate. Sufficient conditions explained $86.4 \%$ of the empirical evidence. The six configurations are shown in Table 6 and the configurations of the brand-switching intention are shown in Table 7. From these results, it can be seen that the most important configurations of brand-switching intention are negative brand value recognition * negative brand image recognition, and alternative attractiveness * negative brand emotion * negative brand value recognition, as they represent the highest raw coverage values.

Table 7. The configurations of the brand-switching intention.

\begin{tabular}{ccccccc}
\hline Construct & M1 & M2 & M3 & M4 & M5 & M6 \\
\hline aa & $\bullet$ & $\otimes$ & & & $\bullet$ & $\bullet$ \\
nbi & $\bullet$ & & & & & $\bullet$ \\
nbv & $\bullet$ & & $\otimes$ & $\bullet$ & $\bullet$ & \\
nbe & & $\otimes$ & $\otimes$ & $\otimes$ & $\bullet$ & \\
wa & & $\otimes$ & $\bullet$ & $\otimes$ & & $\bullet$ \\
raw coverage & 0.916 & 0.305 & 0.315 & 0.323 & 0.823 & 0.792 \\
unique coverage & 0.063 & 0.001 & 0.001 & 0.001 & 0.014 & 0.015 \\
consistency & 0.949 & 0.840 & 0.925 & 0.934 & 0.981 & 0.968 \\
overall solution coverage & \multicolumn{7}{c}{0.954} \\
overall solution consistency & \multicolumn{7}{c}{0.894} \\
frequency cutoff & \multicolumn{7}{c}{0.864} \\
consistency cutoff & & & & & \\
\hline
\end{tabular}




\section{Discussion}

\subsection{Key Findings}

This study is based on the cognition theory and the framework of brand intention, and investigates the mechanism and configuration of brand-switching intention in the context of e-commerce from the viewpoints of cognition and emotion.

Firstly, it shows that alternative attractiveness can influence negative brand image recognition and negative brand value recognition, and negative brand recognition has an effect on negative brand emotion which can lead to a brand-switching intention. Previous literature studied brand-switching intention by considering factors such as switching barriers, customer satisfaction [34] and relationship quality [43], thus lacking an investigation of both external and internal factors. Our findings enrich the study of brand-switching intention by taking a more comprehensive approach. The quantitative study identifies the mechanisms of brand-switching intention from factors both inside and outside the brand. First, from the outside, it shows that alternative attractiveness influences both negative brand image recognition and negative brand value recognition, which expands upon the study of brand-switching intention considering only inside factors [34]. Second, from the inside, negative brand recognition can lead to negative brand emotion, which can further positively influence brand-switching intention. It is also shown that the effect of negative brand image recognition on negative brand emotion was smaller than the effect of negative brand value recognition on negative brand emotion; the reason behind this might be that brand value is much more important for customers when shopping online. Third, it is shown that the effect of brand recognition on brand-switching intention is partially mediated through brand emotion. Negative brand emotion mediates the relationship between negative brand image recognition and brand-switching intention as well as the relationship between negative brand value recognition and brand-switching intention, which comprehensively integrates the role of emotion in switching intention [44]. It is shown that brand recognition could influence brand-switching intention directly and it could also have an effect on brand-switching intention indirectly through brand emotion.

Secondly, this study identifies six configurations of brand-switching intention using qualitative comparative analysis [45]. Previous studies regard the influencing factors independently and lack the investigation of valid configurations of brand-switching intention [46]. This study uses a qualitative method to analyze the configuration of brand-switching intention. The qualitative comparative analysis results show that the fsQCA model explained brand-switching intention $(86.4 \%$ of the variance) better than the SEM method ( $74.2 \%$ of the variance). There are six configurations of brand-switching intention: (1) negative brand value recognition * negative brand image recognition, (2) not alternative attractiveness * not website anxiety * not negative brand emotion, (3) website anxiety * not negative brand emotion * not negative brand value recognition, (4) not website anxiety * not negative brand emotion * negative brand value recognition, (5) alternative attractiveness * negative brand emotion * negative brand value recognition, and (6) alternative attractiveness * website anxiety * negative brand image recognition. The intermediate solution explained $86.4 \%$ of the brand-switching intention. It indicated that the generation of brand-switching intention was the mutual result of alternative attractiveness, negative brand image recognition, negative brand value recognition, negative brand emotion and website anxiety, adding to the hypothesis in the SEM method which lacked an investigation of the mutual effects of these factors.

\subsection{Theoretical Implications}

This study is based on cognition theory and the framework of brand intention, and it has some theoretical value for future research.

Firstly, the study enriches the cognition theory by investigating the antecedents of brand-switching intention. Prior studies mainly regard the cognition theory as a theoretical base in human cognition [47], however there lacks of studies of customer switching behavior building on cognition theory. The context of e-commerce includes many choices [48], so cognition plays a significant role in individual 
behavior. In this study, it is affirmed that brand image recognition and brand value recognition play a significant role in brand emotion and brand-switching intention. It broadens the cognition theory to the research context of e-commerce by applying cognition theory to the investigation of brand-switching intention.

Secondly, the study enriches the mechanism of brand-switching intention in e-commerce. Prior studies have investigated the factors influencing brand-switching intention, but these researches mainly focus on factors inside the brand [43]; scant studies take the role of alternative attractiveness into consideration. This study investigates brand-switching intentions from factors both inside and outside of the brand. The results show that alternative attractiveness could significantly influence brand recognition and brand-switching intention. This broadens the investigation of brand-switching intention to outside the brand and pushes the study of brand-switching intention towards a more comprehensive viewpoint.

Thirdly, the study finds six configurations of brand-switching intention. In the context of e-commerce, much research has investigated the factors influencing customer brand-switching intention [46]. However, these studies regard the factors independently and were unable to identify the configuration of brand-switching intention. This study takes a qualitative approach to investigate how brand-switching intentions are formed and thus broadens the current literature on brand-switching. Thus, this study identifies the valid path leading to a brand-switching intention, enriching understanding of the configuration of brand-switching intention in e-commerce.

\subsection{Practical Implications}

The study also has some practical value. Firstly, it is highly important for brand vendors to enhance brand recognition in both the image and value aspects. Due to the fact that brand-switching intention damages enterprise profits and development, it is essential to take some measures to enhance brand recognition, for example, establishing brand marketing strategies and providing attractive activities for customers. Secondly, it is of vital importance to understand consumer psychology and thus to enhance brand emotion. Strong brand emotion could help to decrease brand-switching intention, and brand managers should attach more importance to enhancing it. For example, in order to increase customers' brand emotion, brand vendors should devote more energy to building healthy relationships with customers, providing discounts for existing customers and increasing the product quality in order to increase customer loyalty. Lastly, the role of brand alternatives in the context of e-commerce should not be ignored. Highly attractive alternative products can decrease brand image recognition and brand value recognition, indirectly increasing brand-switching intention. It is essential for brand marketers to survey the market situation from a comprehensive viewpoint in order to execute appropriate marketing tactics at the right time. Alternatives always pose potential threats to a particular brand, and keeping a watchful eye on the competition and adjusting marketing plans and strategies is a never-ending task.

\section{Limitations and Future Research}

This study has some limitations that need further exploration. Firstly, the data of the constructs used in this study was self-reported and might contain some biases. The measurement of alternative attractiveness, website anxiety, brand recognition and emotion, and brand-switching intention is based on subjective responses. It captures customer feelings but lacks longitudinal analysis of customer behavior. Future researchers could collect online review texts to analyze objective data, and combine subjective and objective data to help understand brand-switching intention more comprehensively.

Secondly, customer brand-switching behavior is a complicated process. This study only studies brand-switching from the perspective of alternative attractiveness, and considers customers' brand recognition, emotion and anxiety. Brand emotion is regarded as a single-dimension construct in this study; however, there are different emotions involved when engaging in e-commerce, such as liking, disliking and neutrality, that might vary in their effects on an individual's behavior. Thus, future 
studies could take different brand emotions into consideration to explore the effects of various emotions on brand-switching intention. Furthermore, future studies could also consider other factors affecting brand-switching intention, such as word-of-mouth, and the service quality of brand merchants.

Finally, as a new method to analyze path configuration, the fsQCA method has received much attention in the field of psychology, but there is limited research using this method in the management field. Future research in various fields could employ fsQCA so as to understand the necessary conditions and configurations leading to certain behavior.

Author Contributions: X.Z. and X.Y.D. conceptualization and designed the work. X.Y.D. and L.M. were accountable for conducting research and drafting the manuscript. X.Y.D. and G.S.W. were responsible for statistical analysis. The authors of this manuscript approved the content of this manuscript.

Funding: This research was funded by National Social Science Foundation of China, grant number 16AJY003, 17BGL198 and 18BGL263 for their support during this research.

Acknowledgments: The authors are grateful to the editor of sustainability for their suggestions to this research.

Conflicts of Interest: The authors declare no conflict of interest.

\section{References}

1. Seres-Huszarik, E.; Jozsa, L.; Toth, Z. Factors determining the development of business relationships in the advertising market. Acta Polytech. Hung. 2017, 14, 65-82.

2. Brodie, R.J.; Glynn, M.S.; Little, V. The service brand and the service-dominant logic: Missing fundamental premise or the need for stronger theory? Mark. Theory 2006, 6, 363-379. [CrossRef]

3. $\mathrm{Xu}, \mathrm{H} . ;$ Teo, H.H.; Tan, B.; Agarwal, R. The role of push-pull technology in privacy calculus: The case of location-based services. J. Manag. Inf. Syst. 2009, 26, 135-174. [CrossRef]

4. Cheng, Q.; Du, R.S.; Ma, Y.F. Factors influencing theme park visitor brand-switching behaviour as based on visitor perception. Curr. Issues Tour. 2016, 19, 1425-1446. [CrossRef]

5. Shiue, Y.C.; Li, L.S.H. Brand involvement in retaining customers despite dissatisfaction. Soc. Behav. Pers. 2013, 41, 643-650. [CrossRef]

6. Hwang, I.; Kwon, H. Effects of demotion in loyalty programs on brand-switching intentions. Serv. Bus. 2016, 10, 489-505. [CrossRef]

7. Ghazali, E.; Nguyen, B.; Mutum, D.S.; Mohd-Any, A.A. Constructing online switching barriers: Examining the effects of switching costs and alternative attractiveness on e-store loyalty in online pure-play retailers. Electron. Mark. 2016, 26, 157-171. [CrossRef]

8. Wyer, K., Jr.; Srull, T. Human cognition in its social context. Psychol Rev. 1986, 93, 322-359. [CrossRef]

9. Nepomuceno, M.V.; Laroche, M.; Richard, M.O. How to reduce perceived risk when buying online: The interactions between intangibility, product knowledge, brand familiarity, privacy and security concerns. J. Retail. Consum. Serv. 2014, 21, 619-629. [CrossRef]

10. Kervyn, N.; Fiske, S.T.; Malone, C. Brands as intentional agents framework: How perceived intentions and ability can map brand perception. J. Consum. Psychol. 2012, 22, 166-176. [CrossRef]

11. Walther, J.B.; Brandon, V.D.H.; Ramirez, A.; Burgoon, J.K.; Peña, J. Interpersonal and hyperpersonal dimensions of computer-mediated communication. In The Handbook of the Psychology of Communication Technology; John Wiley \& Sons: Hoboken, NJ, USA, 2015; Volume 1, pp. 1-22.

12. Schmitt, B. The consumer psychology of brands. J. Consum. Psychol. 2012, 22, 7-17. [CrossRef]

13. Roseman, I.J.; Wiest, C.; Swartz, T.S. Phenomenology, behaviors, and goals differentiate discrete emotions. J. Pers. Soc. Psychol. 1994, 67, 206-221. [CrossRef]

14. Merz, M.A.; Zarantonello, L.; Grappi, S. How valuable are your customers in the brand value co-creation process? The development of a customer co-creation value scale. J. Bus. Res. 2018, 82, 79-89. [CrossRef]

15. Hwang, Y.J.; Ballouli, K.; So, K.; Heere, B. Effects of brand congruity and game difficulty on gamers' response to advertising in sport video games. J. Sport Manag. 2017, 31, 480-496. [CrossRef]

16. Jones, M.A.; Mothersbaugh, D.L.; Beatty, S.E. Switching barriers and repurchase intentions in services. J. Retail. 2000, 76, 259-274. [CrossRef]

17. Aaker, D.A. Measuring Brand equity across products and markets. Calif. Manag. Rev. 1996, 38, 102-120. [CrossRef] 
18. Porter, S.S.; Claycomb, C. The influence of brand recognition on retail store image. J. Prod. Brand Manag. 1997, 6, 373-387. [CrossRef]

19. Alexander, B.; Jeffrey, H.; Yanxin, P.; Richard, G.; Panos, Y.P. Balancing design freedom and brand recognition in the evolution of automotive brand styling. Des. Sci. 2015, 2, 1-28.

20. Diamantopoulos, A.; Florack, A.; Halkias, G.; Palcu, J. Explicit versus implicit country stereotypes as predictors of product preferences: Insights from the stereotype content model. J. Int. Bus. Stud. 2017, 48, 1023-1036. [CrossRef]

21. Sierra, V.; Iglesias, O.; Markovic, S.; Singh, J.J. Does ethical image build equity in corporate services brands? the influence of customer perceived ethicality on affect, perceived quality, and equity. J. Bus. Ethics. 2017, 144, 661-676. [CrossRef]

22. Bennur, S.; Jin, B. The mediating role of brand trust and affect in clothing brand loyalty formation: A cross-cultural examination of US and India. J. Text. Inst. 2017, 108, 1-9. [CrossRef]

23. Orzan, G.; Platon, O.E.; Stefanescu, C.D.; Orzan, M. Conceptual model regarding the influence of social media marketing communication on brand trust, brand affect and brand loyalty. Econ. Comput. Econ. Cybern. Stud. 2016, 50, 141-156.

24. Hind, D.; Roper, S.; Abosag, I. Examining the relationship between brand emotion and brand extension among supporters of professional football clubs. Eur. J. Mark. 2012, 46, 1233-1251.

25. $\mathrm{Xu}, \mathrm{J}$. Retaining customers by utilizing technology-facilitated chat: Mitigating website anxiety and task complexity. Inf. Manag. 2016, 53, 554-569. [CrossRef]

26. Nagar, K.; Gandotra, P. Exploring choice overload, internet shopping anxiety, variety seeking and online shopping adoption relationship: Evidence from online fashion stores. Glob. Bus. Rev. 2016, 17, 851-869. [CrossRef]

27. Elhai, J.D.; Levine, J.C.; Dvorak, R.D.; Hall, B.J. Non-social features of smartphone use are most related to depression, anxiety and problematic smartphone use. Comput. Hum. Behav. 2017, 69, 75-82. [CrossRef]

28. Elhai, J.D.; Tiamiyu, M.; Weeks, J. Depression and social anxiety in relation to problematic smartphone use: The prominent role of rumination. Internet Res. 2018, 28, 315-332. [CrossRef]

29. Jon, D.E.; Jason, C.L.; Brian, J.H. Anxiety about electronic data hacking: Predictors and relations with digital privacy protection behavior. Internet Res. 2017, 27, 631-649.

30. Keller, K.L. Conceptualizing, measuring, and managing customer-based brand equity. J. Mark. 1993, 57, 1-22. [CrossRef]

31. Spiteri, J.M.; Dion, P.A. Customer value, overall satisfaction, end-user loyalty, and market performance in detail intensive industries. Ind. Mark. Manag. 2004, 33, 675-687. [CrossRef]

32. Ping, R., Jr. The Effects of Satisfaction and Structural Constraints on retailer exiting, voice, loyalty, opportunism, and neglect. J. Retail. 1993, 69, 320-352. [CrossRef]

33. Thomson, M.; Macinnis, D.J.; Park, C.W. The ties that bind: Measuring the strength of consumers' emotional attachments to brands. J. Consum. Psychol. 2005, 15, 77-91. [CrossRef]

34. Han, H.; Kim, W.; Hyun, S.S. Switching intention model development: Role of service performances, customer satisfaction, and switching barriers in the hotel industry. Int. J. Hosp. Manag. 2011, 30, 619-629. [CrossRef]

35. Ma, L.; Zhang, X.; Ding, X.; Wang, G. Bike sharing and users' subjective well-being: An empirical study in China. Transp. Res. Part A Policy Pract. 2018, 118, 14-24. [CrossRef]

36. Ma, L.; Zhang, X.; Ding, X.Y. Social media users' share intention and subjective well-being: An empirical study based on WeChat. Online Inf. Rev. 2018, 784-801. [CrossRef]

37. Nunnally, J.C.; Bernstein, I.H. Psychometric theory. Am. Educ. Res. J. 1994, 5, 1-83.

38. Woodside, A.G.; Hsu, S.Y.; Marshall, R. General theory of cultures' consequences on international tourism behavior. J. Bus. Res. 2011, 64, 785-799. [CrossRef]

39. Morgan, S.L. Redesigning social inquiry: Fuzzy sets and beyond. Soc. Forces 2010, 88, 1936-1938.

40. Schneider, M.R.; Schulze-Bentrop, C.; Paunescu, M. Mapping the institutional capital of high-tech firms: A fuzzy-set analysis of capitalist variety and export performance. J. Int. Bus. Stud. 2010, 41, 246-266. [CrossRef]

41. Skaaning, S.E. Assessing the robustness of crisp-set and fuzzy-set QCA results. Sociol. Methods Res. 2011, 40, 391-408. [CrossRef] 
42. Eng, S.; Woodside, A.G. Configural analysis of the drinking man: Fuzzy-set qualitative comparative analyses. Addict. Behav. 2012, 37, 541-543. [CrossRef] [PubMed]

43. Marimuthu, M. Influence of perceived service fairness on relationship quality and switching intention: An empirical study of restaurant experiences. Curr. Issues Tour. 2016, 19, 1005-1026.

44. Han, H.; Back, K.J.; Barrett, B. Influencing factors on restaurant customers' revisit intention: The roles of emotions and switching barriers. Int. J. Hosp. Manag. 2009, 28, 563-572. [CrossRef]

45. Zhang, X. Knowledge management system use and job performance: A multilevel contingency model. MIS Q. 2017, 41, 811-840. [CrossRef]

46. Kordi Ghasrodashti, E. Explaining brand switching behavior using pull-push-mooring theory and the theory of reasoned action. J. Brand Manag. 2018, 25, 293-304. [CrossRef]

47. Bandura, A. Social cognitive theory: An agentic perspective. Annu. Rev. Psychol. 2001, 52, 1-26. [CrossRef] [PubMed]

48. Pilli, L.E.; Mazzon, J.A. Information overload, choice deferral, and moderating role of need for cognition: Empirical evidence. Rev. Adm. 2016, 51, 36-55.

(C) 2018 by the authors. Licensee MDPI, Basel, Switzerland. This article is an open access article distributed under the terms and conditions of the Creative Commons Attribution (CC BY) license (http:/ / creativecommons.org/licenses/by/4.0/). 